\title{
Cell Surface Display of Red-Grouper Nervous Necrosis Virus Capsid Protein on Pichia pastoris
}

\author{
Uraiwan Intamaso ${ }^{1}$, Palatip Chutoam ${ }^{1}$, Witthaya Poomipak ${ }^{2}$, Nopadon Pirarat ${ }^{3}$ \\ ${ }^{1}$ Faculty of Allied Health Sciences, Burapha University, Chonburi, Thailand \\ ${ }^{2}$ Faculty of Medicine, Chulalongkorn University, Bangkok, Thailand \\ ${ }^{3}$ Faculty of Veterinary Sciences, Chulalongkorn University, Bangkok, Thailand \\ Email: *uintamaso@yahoo.com, *uraiwani@buu.ac.th, palatip.ch@go.buu.ac.th, ulcer_13@hotmail.com, \\ noppadonpirarat@gmail.com
}

How to cite this paper: Intamaso, U., Chutoam, P., Poomipak, W. and Pirarat, N. (2018) Cell Surface Display of Red-Grouper Nervous Necrosis Virus Capsid Protein on Pichia pastoris. Advances in Microbiology, 8, 830-845.

https://doi.org/10.4236/aim.2018.811055

Received: September 11, 2018

Accepted: November 2, 2018

Published: November 5, 2018

Copyright $\odot 2018$ by authors and Scientific Research Publishing Inc. This work is licensed under the Creative Commons Attribution International License (CC BY 4.0).

http://creativecommons.org/licenses/by/4.0/

c) (i) Open Access

\begin{abstract}
Nervous necrosis virus (NNV), the etiological agent of viral nervous necrosis, has a high mortality rate of $100 \%$ in hatchery-reared larvae and juveniles. At present, there are still no effective vaccines available for NNV. Pichia pastoris surface display of viral capsid proteins was generated in hopes of developing an oral vaccine against red-grouper-nervous-necrosis virus (RGNNV) in fish. Fingerlings or juveniles that showed clinical signs of NNV infection were proved by RT-PCR for the appearance of expected length of 198 bpcDNA and further analysis by DNA sequencing. The DNA fragment containing AG $\alpha 1$ linked to RG-NNVRNA2, $2100 \mathrm{bp}$ in length, was inserted into pPIC9K vector. Linearlized plasmids were electroporated into $P$. pastoris GS115 (mut ${ }^{+} \mathrm{His}^{-}$) and yeast isolates that had $\mathrm{Muts}^{-} \mathrm{His}^{+}$and resistance phenotype at $4 \mathrm{mg} / \mathrm{mL}$ geniticin were selected to determine the integration of the target gene by PCR reaction. The extracted cell walls from the yeasts cultured in buffered-methanol-complex medium (BMMY) through an induction of $0.5 \%$ methanol for 6 days, were investigated for the fusion proteins by western blot. A protein band of $73 \mathrm{kDa}$ predicted to be the fusion protein and a non-specific one of $56 \mathrm{kDa}$ were detected. Staining of the fusion proteins expressing cells with corresponding antibodies revealed their presence of NNVRNA2, but varied the intensity of detected signals from cell to cell by confocal laser scanning fluorescence microscopy. The predicted fusion proteins tertiary structure also confirmed exposed conformation of the fusion protein on the cell wall. In this study, the capsid proteins from the red-spotted grouper nervous necrosis virus were successfully expressed on the cell surface of $P$. pastoris but still low levels of fusion protein expression. Further studies are required to optimize fully surface protein expression prior to evaluate the
\end{abstract}


possible use of the constructed recombinant yeast as an oral vaccine against RG-NNV infection.

\section{Keywords}

Nervous Necrosis Virus, Protein Engineering, Protein Expression, P. pastoris, Yeast Surface Display Technology

\section{Introduction}

Aquaculture in Thailand ranks $13^{\text {th }}$ in the world, producing 934.8 million tons of total aquaculture and 19.6 million tons of marine/aquaculture production [1]. Epinephelus spp., or groupers, are in high demand in local and international markets, especially in Singapore and China. Market value and increasing demand have led to growing interest in groupers. However, with rapid development of marine farming activities, outbreaks of viral nervous necrosis (VNN) have affected the grouper aquaculture industry, causing tremendous economic losses and food insecurity [2].

VNN also known as viral encephalopathy and retinopathy (VER) is a well-known disease in more than 30 fish species worldwide, including the grouper species. The disease is caused by nervous necrosis virus (NNV) - a small RNA virus belonging to the genus Betanodavirus, within the family Nodaviridae. The genome comprises two molecules of plus-sense ssRNA, RNA1 and RNA2. The RNA1 gene in the length of $3.1 \mathrm{~kb}$ encodes the $110 \mathrm{kD}$ are replicase for viral replication. RNA2 gene $(1.4 \mathrm{~kb})$ encodes the plentiful coat protein of $42 \mathrm{kDa}$. Based on the DNA sequences of T4 variable region of RNA2, four major genotypes have initially been classified and named depending on the host species origin as Striped jack nervous necrosis virus (SJNNV), tiger puffer nervous necrosis virus (TPNNV), barfin flounder nervous necrosis virus (BFNNV), and red-spotted grouper nervous necrosis virus (RGNNV)-type [3]. An additional genotype, a turbot betanodavirus strain (TNV) [4], and several sub-genotypes [5] that appear to be restricted to geographical locations relating to water temperatures have also been proposed [6]. In Thailand, there have been many outbreaks of RG-NNV infection since 1995 mostly in the southern [7] [8] [9] and recently in the central Thailand [10].

Generally, fish affected by NNV show commonly observed symptoms, including, reduced appetite, dark body and an abnormal swimming pattern. The disease can be transmitted horizontally in healthy fish commonly through co-habitation in contaminated water [11] and vertically from broodstock to offspring evidenced, at least in some species [12] [13] [14] [15]. Generally, the mortality rate varies by age and is more pronounced in larvae stages, often higher than 99\% [11]. Currently there are no effective treatments available. Vaccination is therefore the most appropriate method for the control of disease-causing 
pathogens.

Oral delivery of vaccines has recently emerged as an attractive alternative to injection in developing countries. They enable mass vaccination at a relatively low cost, easy immunization of fish at all stages, and reduce stress from injection site-pain. Despite the many advantages of oral vaccines, the route of immunization hampers the development of oral vaccines [16]. Protection of antigens from deterioration and maintenance of their integrity in the harsh gastro-intestinal environment, are two of the key factors for the development of oral vaccines.

The yeast surface display system has been used for antigen display [17] [18]. A target protein with sizes varying from $93-136 \mathrm{kDa}$ is attached to a cell-membrane bound glycosylphosphatidylinositol (GPI)-anchor protein on the yeast cell wall [19]. The methylotrophic yeast $P$. pastoris surface display has been successfully engineered using the GPI-anchor signal of Ag $\alpha 1 \mathrm{p}$ or Sed1p for N-terminal fusion and Aga2, Flo1p, or Pir1p for C-terminal fusion [20] [21]. P. pastoris can utilize methanol as its sole carbon source under a strong inducible AOX1 promoter to achieve high-level heterologous protein production [22]. Since it secretes low levels of endogenous proteins $P$. pastoris is a much more attractive host than Saccharomyces cerevisiae for heterologous protein expression. In addition, proteins displayed on the $P$. pastoris cell surface were also more likely to be correctly folded, and exhibited better stability than that displayed on the $S$. cerevisiae cell surface [23]. Moreover, it proved to be a good vehicle for delivering antigen to the mucosal epithelium as in bioencapsidated form for larvae fish, and in non-encapsidated form for older fish [24]. Antigen determinants that are expressed on the surface of Pichia could be a good candidate for possible oral vaccines.

This study described the construction of methylotrophic yeast $P$. pastoris cells displaying RG-NNV capsid protein linked to the N-terminus of the $S$. cerevisiae GPI-protein, $\alpha$-agglutinin. Expressed proteins of yeast constructs were characterized by western blot. Immunofluorescence labelling was used to verify the location of the fusion proteins. In addition, tertiary structure of the fusion protein on the yeast surface was also predicted. Their immunogenicity and efficacy in protecting fish against RG-NNV by oral delivery might be tested in further studies.

\section{Materials and Methods}

\subsection{Strains, Media and Plasmid}

JM109 Escherichia coli (endA1, recA1, gyrA96, thi, hsdR17 $\left(\mathrm{rk}^{-}, \mathrm{mk}^{+}\right)$, relA1, supE44, $\Delta$ (lac-proAB), [F' traD36, proAB, laqIqZ $\Delta \mathrm{M} 15]$.) was cultured at $37^{\circ} \mathrm{C}$ in LB medium containing $100 \mu \mathrm{g} / \mathrm{mL}$ of ampicillin for bacterial colony selection. The wild type $S$. cerevisiae strain was a kind gift from Dr. Kanjana Limpeng (Department of Microbiology, Faculty of Sciences, Burapha University). P. pastoris strain GS115 ( $\mathrm{Mut}^{+} \mathrm{His}^{-}$) and P. pastoris expression plasmid pPIC9K were purchased from Invitrogen (Carlsbad, CA). Yeast strains were propagated in yeast extract peptone dextrose (YEPD) medium (Invitrogen), and induced in buffered minimal glycerol medium and buffered minimal methanol medium 
prepared, as recommended by Invitrogen.

\subsection{Detection of RG-NNV by RT-PCR and Sequence Analysis}

Affected fingerlings or juveniles with the clinical signs of skin darkening, and loss of appetite, anorexia and abnormal swimming behavior were collected during a disease outbreak and sent from Faculty of Veterinary Sciences, Chulalongkorn University. One hundred-milligrams of tissues were homogenized using $1 \mathrm{~mL}$ of Trizol reagent (Invitrogen, USA) according to manufacturer's instructions. The RT-PCR reaction were conducted using VNN-F1 and VNN-R primer, specific binding to nucleotide(nt) 139 - 336, the conserved region of coat protein of NNV [25]. According to manufacturer's instructions for the Super Script III One-Step RT-PCR System with Platinum Taq DNA polymerase (Invitrogen, USA), the $25 \mu \mathrm{L}$ of the total reaction was composed of $0.1 \mathrm{pg}-1 \mu \mathrm{g}$ RNA template, $0.4 \mu \mathrm{M}$ forward and reverse primer, $0.4 \mathrm{mM} \mathrm{MgSO}_{4}, 12.5 \mu \mathrm{L} 1 \times$ reaction mix and $1 \mu \mathrm{L}$ Superscript ${ }^{\circ}$ IIIRT/platinum ${ }^{\otimes}$ Taq/mix. The thermocycler condition composed of an initial denaturation step at $55^{\circ} \mathrm{C}$ for $30 \mathrm{~min}$, initial denature step at $94^{\circ} \mathrm{C}$ for $2 \mathrm{~min}$, followed by 35 cycles of $94^{\circ} \mathrm{C}$ for $2 \mathrm{~min}, 60^{\circ} \mathrm{C}$ for $30 \mathrm{~s}$ and $68^{\circ} \mathrm{C}$ for $1 \mathrm{~min}$, and the final extension step at $68^{\circ} \mathrm{C}$ for $5 \mathrm{~min}$. The cDNA product was analyzed with Gene Ruler 100 bp Plus DNA ladder marker (Thermo Scientific, USA) by using $2 \%$ agarose gel electrophoresis stained with 10,000-fold diluted SYBR Gold (Invitrogen, USA). The expected length of 198 base pair (bp) cDNA was extracted from agarose gel and purified using Pure Link Quick PCR Purification kit (Invitrogen). Sense strand was sequenced using the specific forward primer (First BASE Laboratories SdnBhd, Malaysia) to confirm RGNNV genotype based on nucleotide alignment analysis of the open reading frame (ORF) of the RNA2 against other betanoda viruses retrieved from GenBank using PubMed NCBI BLAST program.

\subsection{Construction of Fusion Expression Plasmid Containing AG $\alpha 1$ and RNA2 of RG-NNV}

Genomic DNA of $S$. cerevisiae was isolated using yeast DNA extraction kit (Thermo Fisher Scientific). GPI-anchored protein AG $\alpha$ l ( $\alpha$-agglutinin) was amplified with AG $\alpha 1$ EcoRI F and AG $\alpha 1$ AvrII R primers [26] in the $50 \mu \mathrm{L}$ total reaction which was composed of $5-10 \mathrm{ng}$ genomic DNA, $1 \times$ GC buffer, 0.2 mM dNTPs mix, $0.2 \mu \mathrm{M}$ of each primer and $0.02 \mathrm{U}$ Phusion DNA Polymerase (Thermo Fisher Scientific). The thermocycler condition initial denaturation step was $98^{\circ} \mathrm{C}$ for $3 \mathrm{~min}$, followed by 35 cycles of denaturation $98^{\circ} \mathrm{C}$ for $10 \mathrm{~s}$, annealing $40^{\circ} \mathrm{C}$ for $30 \mathrm{~s}$, extension $72^{\circ} \mathrm{C}$ for $40 \mathrm{~s}$ and final by $72^{\circ} \mathrm{C}$ for $10 \mathrm{~min}$. The $980 \mathrm{bp}$ of expected PCR products with the addition of EcoRI and AvrII, on 5' and 3' terminal end, respectively, were digested with corresponding restriction enzymes and subsequently cloned into the EcoRI and $A$ vrII digested pPIC9K expression vector (Invitrogen, USA). Transformants were selected on LA containing $100 \mu \mathrm{g} / \mathrm{mL}$ amplicin. The identities of plasmids were verified by PCR restriction enzyme digestion, and confirmed by DNA sequencing. The resulting recombinant plasmid 
was designated as pPIC9K-AG $\alpha 1$.

Viral RNAs, isolated from affected fish, were used as templates for reverse transcription to produce a single stranded-cDNA by Super Script ${ }^{\circledast}$ III first-strand synthesis system for RT-PCR (Invitrogen, USA). Ten microliters of the total reaction of $5 \mu \mathrm{M}$ Oligo (dT) primer, $1 \mathrm{mM}$ dNTPs mix and $1 \mathrm{pg}-5 \mu \mathrm{g}$ total RNA were conducted according to the manufacturer's instructions. The first strand of cDNA was further transcribed to produce cDNA with the SnaBI F and MfeI R primers corresponding to nucleotides 1 - $23 \mathrm{nt}$ and 993 - $1014 \mathrm{nt}$ of RG-NNV coat protein, respectively (Table 1) using Phusion DNA Polymerase (Thermo Fisher Scientific). The thermocycler condition initial denaturation was $98^{\circ} \mathrm{C}$ for $30 \mathrm{~s}$, followed by 35 cycels of denaturation $98^{\circ} \mathrm{C}$ for $10 \mathrm{~s}$, annealing $56.4^{\circ} \mathrm{C}$ for $30 \mathrm{~s}$, extension $72^{\circ} \mathrm{C}$ for $40 \mathrm{~s}$ and final by $72^{\circ} \mathrm{C}$ for $10 \mathrm{~min}$. The $1014 \mathrm{bp}$ amplification product containing the partial RNA2 gene of RG-NNV with the addition of SnaBI and MfeI restriction site on 5' and 3' end, respectively was digested with corresponding restriction enzymes, and finally ligated into SnaBI and EcoRI digested pPIC9K-AG $\alpha$-1. pPIC9K-RG-NNVRNA2-AG $\alpha$-1 fusion plasmid at approximate length of 2100 bp was produced. Purified plasmids were verified by PCR using with the alpha factor forward and 3' AOX1 reverse primer (Invitrogen, USA), specific binding to corresponding region on $\mathrm{pPIC} 9 \mathrm{~K}$, and confirmed by DNA sequencing.

\subsection{Construction and Induction of Recombinant Capsid Protein Display Yeast}

Fresh colonies of $P$. pastoris yeast strain GS115 (Mut ${ }^{+} \mathrm{His}^{-}$) (Invitrogen, USA) on Yeast extract peptone dextrose medium (YEPD) plate were cultured in $500 \mathrm{~mL}$ YPD broth at $30^{\circ} \mathrm{C}$ to $\mathrm{OD}_{600}$ of $2.4-3.0$ and collected for the cell pellet by centrifugation at $3000 \times \mathrm{g}, 5 \mathrm{~min}$ at $4^{\circ} \mathrm{C}$. The cell pellet was prepared for competent cells according to manufacturer's instructions (Bio-Rad, USA). Forty microliters of $1 \times 10^{10}$ cells $/ \mathrm{mL}$ competent cells were mixed with $0.1 \mu \mathrm{g} B g / \mathrm{II}$ linearized pPIC9K-RG-NNV RNA2-AG $\alpha$-1 or pPIC9K-AG $\alpha$-1 vector control gently and transferred into $0.2 \mathrm{~cm}$ ice-cold cuvette. The electroporator was pulsed once at the voltage of $2.0 \mathrm{kV}, 5 \mathrm{~ms}$. One milliliter of ice-cold $1.0 \mathrm{M}$ sorbitol was

Table 1. Nucleotide sequences of primers used in this study.

\begin{tabular}{|c|c|c|c|c|}
\hline Name & Sequences & $\operatorname{Tm}$ & Binding sites (nt) & Expected band \\
\hline VNN-F1 & 5’GGATTTGGACGTGCGACCAA 3' & 70.3 & 166 & \multirow{2}{*}{$198 \mathrm{bp}$} \\
\hline VNN-R & 5'CTGAATTTCGAACTCCAGTG 3' & 54.1 & 363 & \\
\hline EcoRI F & 5'-GATGCGAATTCGGTCGGAACCTCG-3' & 76.4 & 442,909 & \multirow{2}{*}{$984 \mathrm{bp}$} \\
\hline AvrII R & 5'-GCCTCAGTCACCTAGGTTAGAATAGCAGGTACGAC-3' & 73.9 & 443,892 & \\
\hline SnaBIF & 5'-GACTGCTACGTAATGGTACGCAAAGGTGAGAAGAA-3' & 75.4 & 4 & \multirow{2}{*}{$1011 \mathrm{bp}$} \\
\hline Mfel R & 5'-CACGTCACAATTGGTTTTCCGAGTCAACCCTAGTG-3' & 79 & 1014 & \\
\hline$\alpha$-Factor F & 5'-TACTATTGCCAGCATTGCTGC-3' & 65 & 1152 & \multirow{2}{*}{$195 \mathrm{bp}$} \\
\hline 3'AOX1 R & 5'-GCAAATGGCATTCTGACATCC-3' & 66.5 & 1347 & \\
\hline
\end{tabular}


immediately added into the mixture and subsequently transferred to $17 \times 100 \mathrm{~mm}$ glass tube for incubation at $30^{\circ} \mathrm{C}$, an hour without shaking. Each colony was selected in sequence on minimal methanol (MM) and minimal dextrose (MD) medium lacking histidine using GS115/ His $^{+}$Muts albumin and GS115/His ${ }^{+}$Muts $\beta$-gal as the vector control. After $30^{\circ} \mathrm{C}$ incubation for 2 days, auxotrophs which grew poorly or showed no growth only on MM plate were selected as MutsHis ${ }^{+}$ auxotrophs. False positive colonies were also excluded by plating $\mathrm{MutsHis}^{+}$colonies onto YEPD medium containing up to $4 \mathrm{mg} / \mathrm{mL}$ G418 antibiotic (Invitrogen). Genomic DNA were extracted and sequenced to determine for correct genomic DNA integration of the expression vectors by PCR, with $\alpha$-Factor F and 3'AOX1 R primer (Invitrogen, USA) pPIC9K-RG-NNVRNA2-AG $\alpha 1$ or pPIC9K-AG $\alpha 1$ integrated yeasts were grown at $28^{\circ} \mathrm{C}$ overnight in $50 \mathrm{~mL}$ buffered minimal glycerol-complex medium (BMGY) to an $\mathrm{OD}_{600}$ of 2 - 6. After centrifugation and resuspension in $1 / 10$ buffered minimal methanol complex medium (BMMY) to an $\mathrm{OD}_{600}$ of 1 , the constructs were grown at $28^{\circ} \mathrm{C}$ in a shaking incubator. Methanol was added every $24 \mathrm{~h}$ to maintain a $0.5 \%$ of methanol concentration. Cells were harvested after 6 days, and cell pellets were stored at $-80^{\circ} \mathrm{C}$ until use.

\subsection{Western Blot}

Proteins of yeast cell walls were extracted from $5-10 \times 10^{6}$ cells using $1 \mathrm{~mL}$ of Trizol reagent (Invitrogen, USA) with protease inhibitor cocktail (Thermo Scientific, USA) in the ratio of 100:1 and followed manufacturer's instructions. Twenty nanograms of total proteins were separated on 5\% - 10\% SDS polyacrylamide gel electrophoresis. After being transferred to polyvinylidene-difluoride membranes using transfer buffer $[20 \mathrm{mM}$ Tris, $150 \mathrm{mM}$ glycine, $0.05 \%(\mathrm{w} / \mathrm{v})$ SDS; $20 \%(\mathrm{v} / \mathrm{v})$ methanol] at $50 \mathrm{~V}$ overnight, membranes were briefly washed with $1 \times$ buffer followed by incubated with 1000 -fold diluted primary antibody (anti-rabbit NNV) for $1.30 \mathrm{~h}$ at room temperature followed by incubating with Optimized HRP reagent working dilution (Piece Fast Western Blot Kit, Super Signal West Pico Substrate, Rabbit Thermo Fisher Scientific) for 30 mins at room temperature. After three 5-min washes in $1 \times$ wash buffer, the membranes were incubated with KPL 1-Component TMB Membrane Peroxidase Substrate (seracare) for $10 \mathrm{mins}$ at room temperature or until protein bands were visualized.

\subsection{Immunofluorescence Labeling of Recombinant Yeast}

The display of the RNA2NNV on the cell wall of P. pastoris was determined by immunofluorescence labeling. Cells were washed in water twice, applied to glass slides, and fixed with $100 \%$ acetone for 3 mins. Fixed slides were washed in $1 \times$ phosphate buffered saline (PBS) and then incubated with 1:1000 primary antibody (anti-rabbit NNV) at $4^{\circ} \mathrm{C}$ overnight. After washing three times with $1 \times$ PBS, slides were incubated with Anti-RbIgG $(\mathrm{H}+\mathrm{L}), \mathrm{F}(\mathrm{ab}$ ')2 Fragment (Alexa Fluor $^{\circledR} 488$ Conjugate) 500 -fold diluted in $1 \times$ PBS for $1 \mathrm{~h}$ at room temperature 
and then washed again three times in $1 \times$ PBS. Fluorescence-labelled cells were then examined under a confocal laser-scanning microscope LSM 800 (Carl Zeiss, Germany). A recombinant yeast transformed with an empty vector was used as a negative control.

\subsection{The Fusion Protein Tertiary Structure Prediction by Bioinformatics}

Tertiary structure of the fusion protein containing 685 residues was predicted online by I-TASSER server, which is an online platform that implements the I-TASSER based-algorithms for protein structure and function predictions [27] [28] [29].

\section{Results and Discussion}

\subsection{Detection of RGNNV Infection in Affected Fishes by RT-PCR and Sequencing}

Total RNA from tissues of affected fingerlings or juveniles showing clinical signs were extracted and analyzed by RT-PCR. A target cDNA band of approximately $198 \mathrm{bp}$ on agarose gel electrophoresis was obtained from the amplification of only one affected tissues (Figure 1), and therefore selected to be used for next experimental steps. RNA2 forms a major ORF of capsid protein that is responsible for the host-specificity observed among Betanodavirus isolates. It consists of a highly conserved region and a variable region. For screening NNV infection, primers were designed based on the DNA sequence of the conserved region among fish nodaviruses [25]. DNA sequencing analysis from amplified cDNA showed 92\% nucleotide sequence homology to RG-NNV retrieved from Genbank database but showed homology to a lesser extent of $81 \%, 83 \%$ and $83 \%$ to BFNNV, SJNNV and TPNNV, respectively (data not shown). Therefore, DNA sequencing analysis finally confirmed the RG-NNV infection.

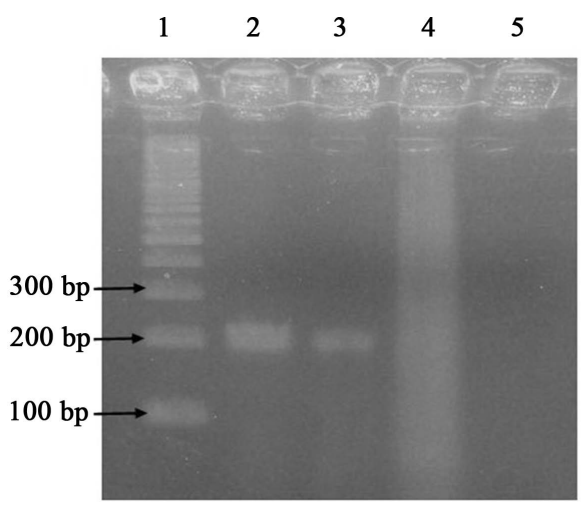

Figure 1. Detection of NNV infection in affected fishes by RT-PCR. The RT-PCR reactions were conducted using VNN-F1 and VNN-R, specific binding to nucleotide 139 336, the conserved region of coat protein of NNV. Expected $198 \mathrm{bp}$ of cDNA product was analyzed by using 2\% agarose gel electrophoresis. Lane 1: 100 bp marker; Lane 2: cDNA (positive control); Lane 3: Tissues from affected fish 1; Lane 4: Tissues from affected fish 2; Lane 5: $\mathrm{dH}_{2} \mathrm{O}$ (negative control). 


\subsection{Construction of Expression Plasmid Harboring RG-NNVRNA2-AG $\alpha 1$ Fusion Gene}

In order to construct yeast surface display for antigen, the commercially available pPIC9K expression vector was first used to generate RG-NNVRNA2-AG $\alpha 1$ fusion protein (Figure 2). Most $P$. pastoris host strains grow on methanol at the wild-type rate (Mut ${ }^{+}$, methanol utilization plus phenotype) under the control of the methanol inducible alcohol utilization gene (AOX1 and/or 2) promoter. In this study, however, SacI and Sall linearization of the expression plasmid for insertion at 5' AOX1 and His 4, respectively were not allowed to produce GS115 $\mathrm{Mut}^{+}$phenotype. The linearization with $B g I I$, instead, led to the occurrence of a gene replacement at 5 ' AOX1 in such a way that the AOX1 gene was deleted and replaced by the expression cassette and marker gene. This disruption of the AOX1 gene rendered these strains to rely on the transcriptionally weaker AOX2 gene for growth on methanol [30], and, as a result, these strains have a Muts (methanol utilization slow) phenotype. Depending on AOX2 for methanol metabolism, it grows slowly on this carbon source. However, strains with AOX mutations are sometimes better producers of foreign proteins than wild-type strains especially in shake-flask cultures [30] [31] [32].

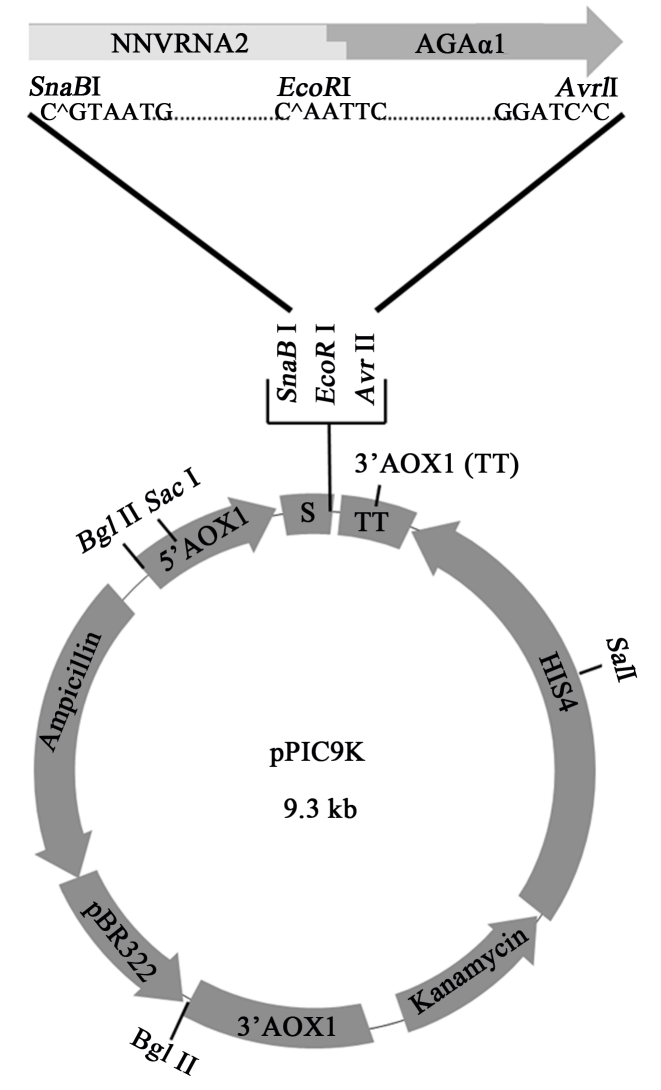

Figure 2. Recombinant $P$. pastoris expression vector for cell surface display of capsid proteins of RG-NNV. RNA2 gene of RG-NNV was fused in frame with the 3' terminus AG $\alpha$ l gene from $S$. cerevisiae, under the control of the methanol-inducible promoter in expression plasmid, pPIC9K. 
The expressed fusion protein contained 338 amino acids of the NNVRNA2, which was fused in frame to the N-terminus (347 amino acids) of the $S$. cerevisiae $\alpha$-agglutinin (AG $\alpha 1$ ) protein. pPIC9K allows the multiple copy of recombinant genes in $P$. pastoris and presumably brings about a subsequent increase in target protein expression. The bacterial kanamycin resistance gene also confers resistance to the related eukaryotic antibiotic G418 or Geneticin [33]. The level of geneticin resistance can be roughly correlated to vector copy number. $P$. pastoris must first be selected on MD lacking histidine for $\mathrm{His}^{+}$phenotypes (can produce histidine); then multicopytransformants are screened by replica-plating to plates containing varying levels of Geneticin'. For Muts phenotype, these gene replacement strains are selected with the reduced ability to grow on methanol. A screen for varying levels of Geneticin resistance was followed in the hope that recombinants, with multiple the copy number of the desired gene, would lead to increased expression of recombinant protein. A strain that contains multiple integrated copies of an expression cassette can sometimes yield more heterologous protein than single-copy strains [34].

\subsection{RG-NNV RNA2 Protein Expression}

In order to examine potential expression strains for the foreign gene product, the time-course induction was conducted. Individual clones and a yeast display vector, pPIC9K-AG $\alpha 1$ control were extracted at different time points and analyzed by dot bot analysis. Results showed that signal intensities varied among individuals. The induction time point of 6 days is probably the best time point for all inducing RG-NNVRNA2 with $0.5 \%$ methanol (data not shown). To confirm the identity of spot proteins, crude extracts from selected yeast clones were subsequently separated on 10\% SDS-PAGE gel and immunoblotted for NNVRNA2. No protein band was seen in yeast cell extracts from Pichia GS115 transfected with the control vector. Two protein bands were visualized, one with molecular weight (MW) of $73 \mathrm{kDa}$ and one with $56 \mathrm{kDa}$ (Figure 3). The appearance of $73 \mathrm{kDa}$ protein band that was predicted to be the fusion proteins, demonstrated the specific binding of those with an NNV polyclonal antibody. Possible cleavage sites of Kex2 end opeptidase and STEl3 protease, the proteases in the yeast secretory process [35], could not be detected from the deduced amino acid sequences of the fusion protein. Thus, the protein band of $56 \mathrm{kDa}$ was presumably the non-specific binding of NNV polyclonal antibody in Western blot.

It was noted that differences in expression levels were observed among constructs containing the fusion gene (Figure 3, lane 3 -6). In this study, all constructs were selected from YEPD medium containing $4 \mathrm{mg} / \mathrm{mL} \mathrm{G418}$ antibiotic whose level of geneticin resistance could be roughly correlated to the multiple copy number of the desired gene. This observation suggests that the multiple copy number of genes did not relatively correlate with levels of protein expression in the case of RGNNV RNA2. In our case, however, low expression levels of the fusion proteins were detected by western blot analysis. In addition, the yeast-derived proteins are normally posttranslationally modified (glycosylation). 


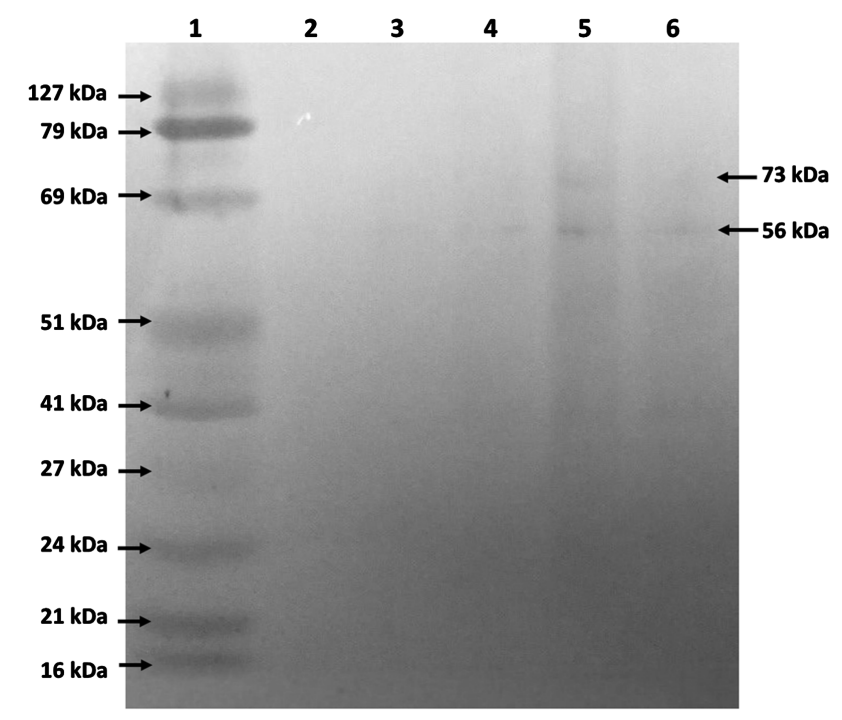

Figure 3. Western blot analysis of the fusion protein expression. Crude extracts of recombinant $P$. pastoris cells expressing either AG $\alpha$, vector control (lane 2) or the fusion protein from each isolates (lane 3 - 6) were tested for the capsid protein of RG-NNV. Cells were extracted and each $20 \mathrm{ng}$ total protein per lane was run on a $10 \%$ SDS-PAGE gel. Signal protein bands were detected using 1000-fold diluted primary antibody (anti-rabbit NNV). Arrows shows the molecular weight of the fusion protein at $73 \mathrm{kDa}$.

Based on molecular weight prediction by NetNGlyc 1.0 program, the coat proteins of RG-NNV also encompassed $4 \mathrm{~N}$-link glycosylation sites. It is likely that the fusion protein with slightly increasing molecular weight could not be observed on $10 \%$ SDS-PAGE.

\subsection{RG-NNV RNA2 Correctly Folded and Immobilized on Yeast Surface}

The surface display of the coat protein of RG-NNV was initially verified by immunofluorescence labeling with a polyclonal antibody against NNVRNA2 as the first antibody, and AlexaFluor488-conjugated goat anti-rabbit IgG, as the second antibody (impenetrate to the cell membrane). Clear fluorescence of AlexaFluor 488 was clearly observed, but not the control cells expressing AG $\alpha 1$ (data not shown). Furthermore, confocal laser scanning fluorescence microscopy was carried out to visualize the location of the fusion proteins. The intensity of detected signals from stained cells varied from cell to cell. Some of these transfected cells displayed signals for protein expression, uniformly distributing in the cell cytoplasm, but some displayed only on the yeast cell surface. Low levels of the fusion protein expression were also observed that agreed with the western blot result. These results indicated that the fusion proteins correctly folded on the yeast cell walls, but had differences in expression levels among the individual cells (Figure 4).

The fusion protein tertiary structure was predicted by the I-TASSER server. The input amino acid sequence of the fusion protein (685 residues) contained a total of $4 \%$ Helix, $15 \%$ beta-sheet and $81 \%$ loops. The predicted tertiary structure 


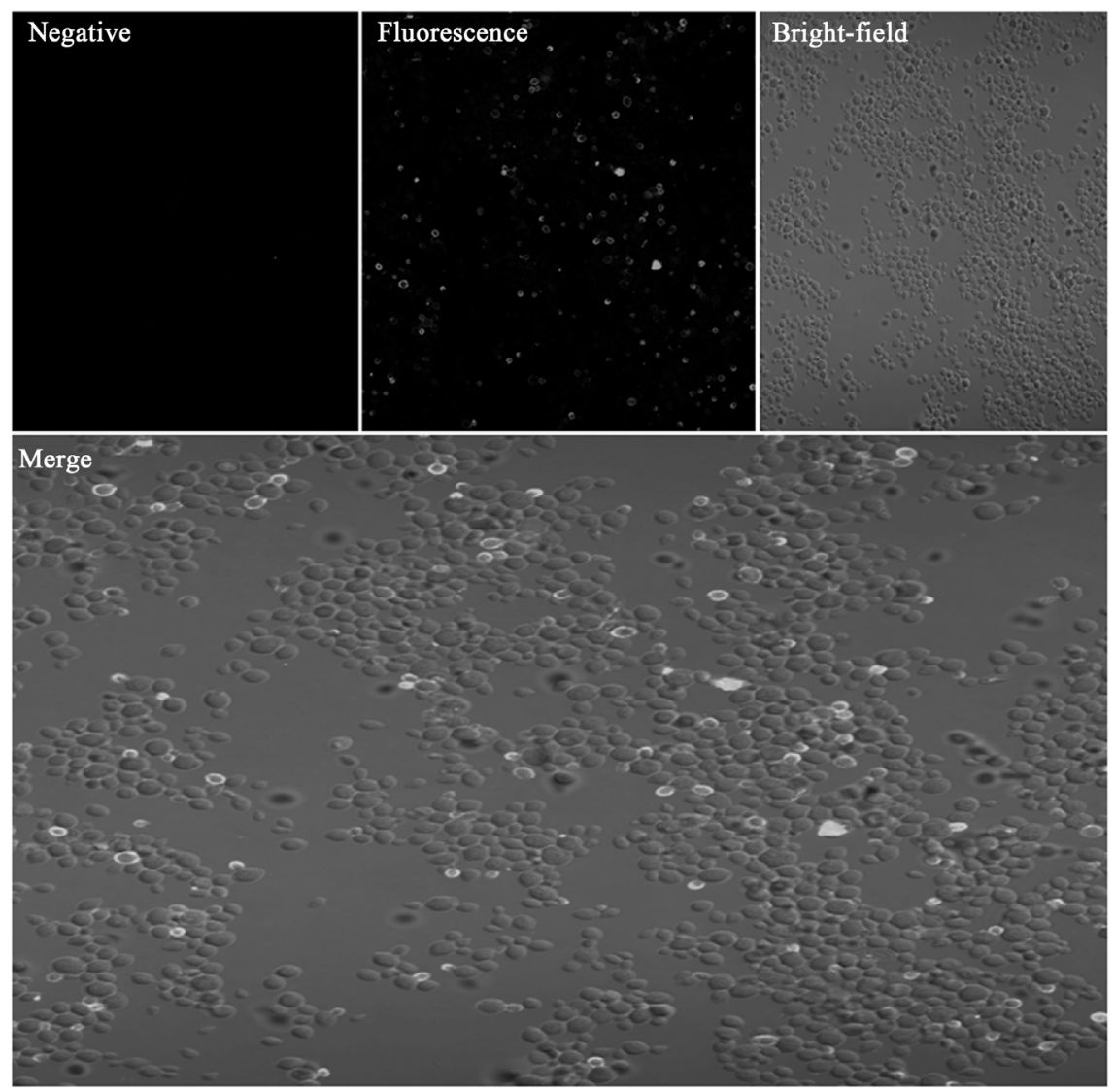

Figure 4. The fusion proteins immobilized on yeast surface by Immunofluorescense labelling. The fusion proteins on cell surfaces were tested for RG-NNV RNA2 protein expression using primary antibody (anti-rabbit NNV) with Anti-RbIgG $(\mathrm{H}+\mathrm{L}), \mathrm{F}(\mathrm{ab}) 2$ Fragment (Alexa Fluor ${ }^{\circledR} 488$ Conjugate. Recombinant $P$. pastoris cells expressing either AG $\alpha$ 1, vector control (Negative, upper left panel) or the fusion proteins were stained using the anti-NNV antibody. Fluorescence microscopic images (upper middle panel), Bright-field images (upper right panel) and Merge (lower panel) were shown.

was composed of 3 domains (C-score equal to -3.44), including domains 1,2 and 3. The tertiary fold of the RG-NNV coat protein subunit was composed of the domain 1 (amino acid 1 - 223), and domain 2 (amino acid 224 - 341). Domain 3 (amino acid 342 - 685) was the GPI-anchored protein AGa1 ( $\alpha$-agglutinin) (Figure 5). Using the crystal structure of the orange-spotted grouper (Epinepheluscoioides) NNV (OGNNV) coat protein as the structural model [36] [37], the tertiary structure of the NNV capsid protein contains two major structural domains. One is the shell (S) domain with a canonical $\beta$-barrel fold and the other is the protruding $(\mathrm{P})$ domain. The $\mathrm{S}$ domain consisted of the $\mathrm{N}$-terminal 213 amino acids. The P domain was composed of 221 to 338 amino acids, connected by linker loops. The $\mathrm{P}$ domain was the most distal part of the folded coat protein and located at the exterior surface of the capsid. The P domain is therefore predicted to contain the antigenic determinants of the immunological response of the host. These results confirmed that $\mathrm{P}$ domain was not obscured in the protein structure and possible exposed to the immune system. 


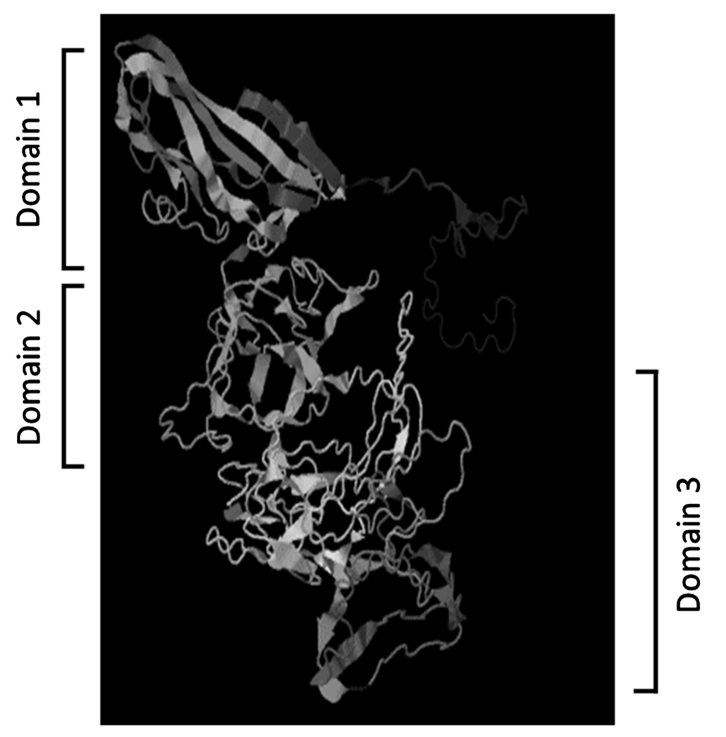

Figure 5. The fusion protein tertiary structure prediction. Ribbon diagram showing the tertiary fold of the RG-NNV coat protein subunit, which was composed of the domain 1 (amino acid 1 - 223) and 2 (amino acid 224 - 341), respectively. Domain 3 (amino acid 342 - 685) was the GPI-anchored protein AGal ( $\alpha$-agglutinin) of $S$. cerevisiae.

As RG-NNVRNA2 was confined to particular domains on the cell surface, surface-immobilized proteins were covalently linked to glucan in the cell wall, rendering them more stable over a period of time. These results confirmed the correct localization, and exposed conformation of the fusion protein on the cell wall for implication as an oral vaccine. Although the proteins expressed on the yeast surface were readily detected with immunofluorescence, the fluorescence intensity varied among cells. Their expression levels might not have been high enough to induce a robust immune response [38]. Codon optimized synthetic genes, encoding the intact form of the coat protein of RG-NNV for P. pastoris, should be designed to improve protein expression [24] [39]. A methanol feed strategy should be optimized in culture under shake flask conditions to achieve the maximum fusion protein expression as well. Recombinant $P$. pastoris displayed the coat protein of RG-NNV will be further evaluated as a potential oral vaccine by testing immunogenicity before test delivery. Moreover, elimination of unwanted DNA from shuttle vectors containing Escherichia coli antibiotic-resistance markers and drug resistance markers, could make it acceptable for food and pharmaceutical applications.

\section{Conclusions}

In this study, the capsid protein from the red-spotted grouper nervous necrosis virus was successfully expressed and preserved its antigenic integrity on the cell surface of $P$. pastoris.

Optimization to achieve the highest expression of yeast-derived NNVRNA2 on the yeast cell surface is also required before testing, for use as an orally delivered antiviral agent against RG-NNV infection. 


\section{Acknowledgements}

This work was financially supported by Agricultural Research Development Agency (Public Organization Grant No. CRP5905010250). This project was successful due to the dedication of Ms. Sirintip Ratthakit and coworkers. I am also thankful to Associate Professor Dr. Sunchai Payungporn Faculty of Medicine, Chulalongkorn University for experimental equipment, and to John Henderson for kindly editing the manuscript.

\section{Conflicts of Interest}

The authors declare no conflicts of interest regarding the publication of this paper.

\section{References}

[1] FAO (2016) The State of World Fisheries and Aquaculture 2016 (SOFIA): Contributing to Food Security and Nutrition for All. The State of World Fisheries and Aquaculture, Rome, 204.

[2] Fukuda, Y.D., Nguyen, H., Furuhashi, M. and Nakai, T. (1996) Mass Mortality of Cultured Sevenband Grouper, Epinephelus septemfasciatus, Associated with Viral Nervous Necrosis. Fish Pathology, 31, 165-170. https://doi.org/10.3147/jsfp.31.165

[3] Nishizawa, T., Furuhashi, M., Nagai, T., Nakai, T. and Muroga, K. (1997) Genomic Classification of Fish Nodaviruses by Molecular Phylogenetic Analysis of the Coat protein Gene. Applied and Environmental Microbiology, 63, 1633-1636.

[4] Johansen, R., Grove, S., Svendsen, A.K., Modahl, I. and Dannevig, B. (2004) A Sequential Study of Pathological Findings in Atlantic Halibut, Hippoglossus hippogIossus (L.), throughout One Year after an Acute Outbreak of Viral Encephalopathy and Retinopathy. Journal of Fish Diseases, 27, 327-341. https://doi.org/10.1111/j.1365-2761.2004.00548.x

[5] Moody, N.J.G, Horwood, P.F., Reynolds, A., Mahony, T.J., Anderson, I.G. and Oakey, H.J. (2009) Phylogenetic Analysis of Betanodavirus Isolates from Australian Finfish. Diseases of Aquatic Organisms, 87, 151-160. https://doi.org/10.3354/dao02130

[6] Nakai, T., Mori, K., Sugaya, T., Nishioka, T., Mushiake, K. and Yamashita, H. (2009) Current Knowledge on Viral Nervous Necrosis (VNN) and Its Causative Betanodaviruses. Israeli Journal of Aquaculture-Bamidgeh, 61, 198-207.

[7] Boonyaratpalin, S., Supamattaya, K., Kasornchandra, J. and Hoffmann, R.W. (1996) Picorna-Like Virus Associated with Mortality and a Spongious Encephalopathy in Grouper Epinephelus malabaricus. Diseases of Aquatic Organisms, 26, 75-80. https://doi.org/10.3354/dao026075

[8] Danayadol, Y. (1995) Viral Nervous Necrosis in Brownspotted Grouper, Epinephelus malabaricus, Cultured in Thailand. Diseases in Asian Aquaculture, 2, 227-233.

[9] Roonngkamnertwongsa, S., Kanchanakhan, S., Danayadol, Y. and Direkbusarakom, S. (2005) Identification of Betanodavirus Isolated from Viral Necrosis Disease in Red-Spotted Grouper, Epinephilus coides Cultured in Thailand Using PCR and Sequence Analysis. In: Walker, P., Lester, R. and Bondad-Reantaso, M.G., Eds., Disease in Asian Aquaculture, Fish Health Section, Asian Fisheries Society, Manila, 207-216.

[10] Keawcharoen, J., Techangamsuwan, S., Ponpornpisit, A., Lombardini, E.D., Pat- 
chimasiri, T. and Pirarat, N. (2015) Genetic Characterization of a Betanodavirus Isolated from a Clinical Disease Outbreak in Farm-Raised Tilapia Oreochromis niloticus (L.) in Thailand. Journal of Fish Diseases, 38, 49-54. https://doi.org/10.1111/jfd.12200

[11] Munday, B.L., Kwang, J. and Moody, N. (2002) Betanodavirus Infections of Teleost Fish: A Review. Journal of Fish Diseases, 25, 127-142. https://doi.org/10.1046/j.1365-2761.2002.00350.x

[12] Comps, M., Pepin, J.F. and Bonami, J.R. (1994) Purification and Characterization of Two Fish Encephalitis Viruses (FEV) Infecting Lates calcarifer and Dicentrarchus labrax. Aquaculture (Netherlands), 123, 1-10.

[13] Mori, K., Mushiake, K. and Arimoto, M. (1998) Control Measures for Viral Nervous Necrosis in STRIPED jack [Pseudocaranx dentex]. Fish Pathology (Japan), 33, 443-444.

[14] Mushiake, K., Nishizawa, T., Nakai, T., Furusawa, I. and Muroga, K. (1994) Control of VNN in Striped Jack: Selection of Spawners Based on the Detection of SJNNV Gene by Polymerase Chain Reaction (PCR). Fish Pathology, 29, 177-182. https://doi.org/10.3147/jsfp.29.177

[15] Watanabe, K.I., Nishizawa, T. and Yoshimizu, M. (2000) Selection of Brood Stock Candidates of Barfin Flounder Using an ELISA System with Recombinant Protein of Barfin Flounder Nervous Necrosis Virus. Diseases of Aquatic Organisms, 41, 219-223. https://doi.org/10.3354/dao041219

[16] Czerkinsky, C. and Holmgren, J. (2009) Enteric Vaccines for the Developing World: A Challenge for Mucosal Immunology. Mucosal Immunology, 2, 284-287. https://doi.org/10.1038/mi.2009.22

[17] Ananphongmanee, V., Srisala, J., Sritunyalucksana, K. and Boonchird, C. (2015) Yeast Surface Display of Two Proteins Previously Shown to Be Protective against White Spot Syndrome Virus (WSSV) in Shrimp. PLoS ONE, 10, e0128764. https://doi.org/10.1371/journal.pone.0128764

[18] Park, M., Suh, S.-S., Hwang, J., Kim, D., Jongbum, P. and Chung, Y-J. (2014) Production of Red-Spotted Grouper Nervous Necrosis Virus (RGNNV) Capsid Protein Using Saccharomyces cerevisiae Surface Display. Journal of Life Science, 24, 995-1000. https://doi.org/10.5352/JLS.2014.24.9.995

[19] Kondo, A. and Ueda, M. (2004) Yeast Cell-Surface Display-Applications of Molecular Display. Applied Microbiology and Biotechnology, 64, 28-40. https://doi.org/10.1007/s00253-003-1492-3

[20] Sakuragi, H., Kuroda, K. and Ueda, M. (2011) Molecular Breeding of Advanced Microorganisms for Biofuel Production. Journal of Biomedicine and Biotechnology, 2011, Article ID: 416931.

[21] Tanaka, T., Yamada, R., Ogino, C. and Kondo, A. (2012) Recent Developments in Yeast Cell Surface Display toward Extended Applications in Biotechnology. Applied Microbiology and Biotechnology, 95, 577-591.

https://doi.org/10.1007/s00253-012-4175-0

[22] Cregg, J.M., Cereghino, J.L., Shi, J. and Higgins, D.R. (2000) Recombinant Protein Expression in Pichia pastoris. Molecular Biotechnology, 16, 23-52. https://doi.org/10.1385/MB:16:1:23

[23] Jiang, Z., Gao, B., Ren, R., Tao, X., Ma, Y. and Wei, D. (2008) Efficient Display of Active Lipase LipB52 with a Pichia pastoris Cell Surface Display System and Comparison with the LipB52 Displayed on Saccharomyces cerevisiae Cell Surface. BMC Biotechnology, 8, 4. https://doi.org/10.1186/1472-6750-8-4 
[24] Embregts, C.W.E., Reyes-Lopez, F., Pall, A.C., Stratmann, A., Tort, L. and Lorenzen, N. (2018) Pichia pastoris Yeast as a Vehicle for Oral Vaccination of Larval and Adult Teleosts. Fish \& Shellfish Immunology. https://doi.org/10.1016/j.fsi.2018.07.033

[25] Nishizawa, T., Mori, K., Furuhashi, M., Nakai, T., Furusawa, I. and Muroga, K. (1995) Comparison of the Coat Protein Genes of Five Fish Nodaviruses, the Causative Agents of Viral Nervous Necrosis in Marine Fish. The Journal of General Virology, 76, 1563-1569. https://doi.org/10.1099/0022-1317-76-7-1563

[26] Wasilenko, J.L., Sarmento, L., Spatz, S. and Pantin-Jackwood, M. (2010) Cell Surface Display of Highly Pathogenic Avian Influenza Virus Hemagglutinin on the Surface of Pichia pastoris Cells Using Alpha-Agglutinin for Production of Oral Vaccines. Biotechnology Progress, 26, 542-547.

[27] Roy, A., Kucukural, A. and Zhang, Y. (2010) I-TASSER: A Unified Platform for Automated Protein Structure and Function Prediction. Nature Protocols, 5, 725-738. https://doi.org/10.1038/nprot.2010.5

[28] Yang, J., Yan, R., Roy, A., Xu, D., Poisson, J. and Zhang, Y. (2015) The I-TASSER Suite: Protein Structure and Function Prediction. Nature Methods, 12, 7-8. https://doi.org/10.1038/nmeth.3213

[29] Zhang, Y. (2008) I-TASSER Server for Protein 3D Structure Prediction. BMC Bioinformatics, 9, 40. https://doi.org/10.1186/1471-2105-9-40

[30] Cregg, J.M. and Madden, K.R. (1987) Development of Yeast Transformation Systems and Construction of Methanol-Utilization-Defective Mutants of Pichia pastori by Gene Disruption.

[31] Chiruvolu, V., Cregg, J.M. and Meagher, M.M. (1997) Recombinant Protein Production in an Alcohol Oxidase-Defective Strain of Pichia pastoris in Fedbatch Fermentations. Enzyme and Microbial Technology, 21, 277-283. https://doi.org/10.1016/S0141-0229(97)00042-2

[32] Tschopp, J.F., Sverlow, G., Kosson, R., Craig, W. and Grinna, L. (1987) High-Level Secretion of Glycosylated Invertase in the Methylotrophic Yeast, Pichia pastoris. Nature Biotechnology, 5, 1305-1308. https://doi.org/10.1038/nbt1287-1305

[33] Scorer, C.A., Clare, J.J., McCombie, W.R., Romanos, M.A. and Sreekrishna, K. (1994) Rapid Selection Using G418 of High Copy Number Transformants of Pichia pastoris for High-Level Foreign Gene Expression. Nature Biotechnology, 12, 181-184. https://doi.org/10.1038/nbt0294-181

[34] Clare, J.J., Romanes, M.A., Rayment, F.B., Rowedder, J.E., Smith, M.A. and Payne, M.M. (1991) Production of Mouse Epidermal Growth Factor in Yeast: High-Level Secretion Using Pichia pastoris Strains Containing Multiple Gene Copies. Gene, 105, 205-212. https://doi.org/10.1016/0378-1119(91)90152-2

[35] Brake, A.J., Merryweather, J.P., Coit, D.G., Heberlein, U.A., Masiarz, F.R. and Mullenbach, G.T. (1984) Alpha-Factor-Directed Synthesis and Secretion of Mature Foreign Proteins in Saccharomyces cerevisiae. Proceedings of the National Academy of Sciences of the United States of America, 81, 4642-4646.

https://doi.org/10.1073/pnas.81.15.4642

[36] Chen, N.-C., Yoshimura, M., Guan, H.-H., Wang, T.-Y., Misumi, Y. and Lin, C.-C. (2015) Crystal Structures of a Piscine Betanodavirus: Mechanisms of Capsid Assembly and Viral Infection. PLoS Pathogens, 11, e1005203. https://doi.org/10.1371/journal.ppat.1005203

[37] Costa, J.Z. and Thompson, K.D. (2016) Understanding the Interaction between Betanodavirus and Its Host for the Development of Prophylactic Measures for Viral 
Encephalopathy and Retinopathy. Fish \& Shellfish Immunology, 53, 35-49. https://doi.org/10.1016/j.fsi.2016.03.033

[38] Schreuder, M.P., Mooren, A.T., Toschka, H.Y., Verrips, C.T. and Klis, F.M. (1996) Immobilizing Proteins on the Surface of Yeast Cells. Trends in Biotechnology, 14, 115-120. https://doi.org/10.1016/0167-7799(96)10017-2

[39] Luu, V.-T., Moon, H.Y., Hwang, J.Y., Kang, B.-K. and Kang, H.A. (2017) Development of Recombinant Yarrowia lipolytica Producing Virus-Like Particles of a Fish Nervous Necrosis Virus. Journal of Microbiology, 55, 655-664.

https://doi.org/10.1007/s12275-017-7218-5 